\title{
NO RASTRO DA ESCRITA DE PROFESSORES EM FORMAÇÃO: DESCREVER PARA REFLETIR
}

\author{
Ana Paula Gonçalves Fioravante ${ }^{1}$ \\ Vanise dos Santos Gomes ${ }^{2}$
}

\begin{abstract}
RESUMO
O presente artigo problematiza resultados de uma pesquisa em nível de mestrado, realizada junto a seis estagiárias do curso de Pedagogia, cuja temática é a escrita na formação inicial de professores. Percorrendo-se dois questionamentos básicos: quais compreensões sobre o registro reflexivo são apresentadas nas escritas dos sujeitos da pesquisa? Que possíveis contribuições exerce a escrita reflexiva na constituição de professoras em formação? As discussões estão fundamentadas a partir da contribuição de autores como Marques, Warschauer, Moraes e Galiazzi entre outros, sendo que a metodologia de análise respaldou-se na análise textual discursiva, de Moraes e Galiazzi. As ideias apresentadas são motivadas pelo título "No rastro da escrita de professores em formação: descrever para refletir", o qual aborda o caráter descritivo do registro de professoras em formação quando na realização do estágio obrigatório do curso de Pedagogia. A partir das discussões realizadas, conclui-se que o registro reflexivo possui um caráter descritivo, o qual contribui para qualificar a avaliação e o planejamento do trabalho docente.
\end{abstract}

Palavras-chave: Escrita reflexiva; Planejamento; Descrição.

\section{IN THE TRAIL OF TEACHER EDUCACTION: DESCRIBING TO REFLECT}

\begin{abstract}
This article discusses results of a study at the master's level held with six trainees of the Faculty of Education, whose theme is the writing on initial teacher education. Two basic questions is running over: which contribution about reflective regsiter are presented in the writings of the research subjects? What possible contributions carries reflective writing in teachers education? The discussions are based on some authors as Marques, Warschauer, Moraes and Galiazzi among others, and the analysis methodology is backed up in Discursive Textual Analysis, Moraes and Galiazzi. The ideas presented are motivated to the title " In the trail of teacher education: describing to reflect", which addresses the descriptive register wrtting by students who are in the last level of the Pedagogy course. It was concluded that the reflective register has a descriptive character, which contributes to qualify the assessment and planning of teaching
\end{abstract}

Keywords: Reflective writing; Planning; Description. 


\section{Para iniciar o debate: breve história da formação de professores no Brasil}

A discussão relativa à formação de professoras não é recente. Segundo Saviani (2009), "no Brasil a questão do preparo de professores emerge de forma explícita após a independência, quando se cogita a organização da instrução popular" (p.143). A trama entre as transformações ocorridas na sociedade a partir de então com as questões pedagógicas possibilita, segundo o autor, identificar seis períodos na história da formação de professores no Brasil, sendo eles:

1. Ensaios intermitentes de formação de professores (1827-1890). Esse período se inicia com o dispositivo da Lei das Escolas de Primeiras Letras, que obrigava os professores a se instruir no método do ensino mútuo, às próprias expensas; estende-se até 1890, quando prevalece o modelo das Escolas Normais.

2. Estabelecimento e expansão do padrão das Escolas Normais (1890-1932), cujo marco inicial é a reforma paulista da Escola Normal tendo como anexo a escola-modelo.

3. Organização dos Institutos de Educação (1932- 1939), cujos marcos são as reformas de Anísio Teixeira no Distrito Federal, em 1932, e de Fernando de Azevedo em São Paulo, em 1933.

4. Organização e implantação dos Cursos de Pedagogia e de Licenciatura e consolidação do modelo das Escolas Normais (1939-1971).

5. Substituição da Escola Normal pela Habilitação Específica de Magistério (1971-1996).

6. Advento dos Institutos Superiores de Educação, Escolas Normais Superiores e o novo perfil do Curso de Pedagogia (1996-2006) (SAVIANI, 2009).

Buscaremos, aqui, traçar algumas breves discussões a respeito do último aspecto citado por Saviani encontrando, aí, um importante respaldo histórico para pensar não apenas na reestruturação curricular dos cursos de pedagogia mas, sobretudo, na introdução de uma importante ferramenta que qualifica a formação de professores no âmbito da educação superior: a escrita.

A implementação da Lei de Diretrizes e Bases da Educação Nacional- LBD, lei 9394/96-, instaurou importantes discussões a respeito da formação de professores no Brasil. Elevou a nível superior a formação de professores da então séries iniciais, passando a ser, sua formação, de responsabilidade de institutos superiores e da universidade (curso de pedagogia). Anterior à lei, a formação docente era composta por duas modalidades: magistério (nível segundo grau) e curso superior (licenciatura)

Saviani (2006, p. 148) tece uma interessante crítica a este respeito, apontando que a Lei, ao introduzir como alternativa aos cursos de pedagogia e licenciatura os institutos superiores de educação e as Escolas Normais Superiores, acabou por sinalizar o que chamou de "tendência ao nivelamento por baixo". Apresenta, este fato, uma contradição instaurada pela própria LDB, uma vez que, por um lado, aponta a não possibilidade de formação docente em nível médio, nos então conhecidos como cursos normais e, por outro lado, cria os Institutos Superiores de Educação e seus cursos normais superior como mecanismo para tal formação.

O reflexo desta tendência acabou por afetar, também, as diretrizes curriculares do curso de pedagogia, homologada em abril de 2006 (Resolução n.1, de 15 de maio de 2006, do Conselho Nacional de Educação - CNE). Isto porque, bem como apontam os 
estudos de Vieira (2007) as reformas educacionais brasileiras levadas a cabo a partir dos anos 90 promoveram um redimensionamento do que se entende por "formação e trabalho docente", ampliando os desafios dos pesquisadores em educação. Segundo a autora:

No âmbito das políticas de formação docente, a formação do pedagogo e dos professores tem sido entendida como importante estratégia para a melhoria da qualidade da educação, contribuindo para as novas exigências do mundo do trabalho [...] Desse modo, no que diz respeito aos professores, a reforma tem acarretado a redefinição do trabalho docente que, em nome de uma suposta profissionalização, afeta significativamente a carreira dos docentes e seu cotidiano de trabalho. Estão em processo de redefinição a formação docente, a forma de gestão de professores por parte do poder público e o cotidiano das escolas públicas de Educação Básica no Brasil (VIEIRA, 2007, pp. 81-82).

No rastro deste movimento, o currículo dos cursos de pedagogia foram reestruturados, adquirindo um caráter, diríamos, polivalente, uma vez que "abraça" a formação do pedagogo não mais respeitando as particulares de cada nível de ensino. De acordo com Scheibe (2007, p. 51):

A organização curricular foi definida segundo os princípios: da docência como base da formação, da flexibilização do currículo e da organização dos conteúdos por meio de diversas formas didáticas. A flexibilização curricular emergiu das propostas do movimento dos educadores como uma necessidade, diante da diversidade da realidade educacional brasileira.

No contexto destas mudanças, cabe questionar: que perfil de pedagogo está sendo formado? Como os cursos de formação de professores passaram a compreender seu papel social diante da formação destes profissionais?

Não se constitui objetivo deste artigo traçar discussões aprofundadas sobre a história da formação de professores, mas sim trazer elementos desta história para contextualizar a defesa da tese de que a escrita, enquanto ferramenta do pensar contribui para a promoção de um processo formativo de professores reflexivos e críticos no que concerne a sua própria formação e atuação profissional. Acreditamos que tal ferramenta imprimi um movimento na contramão da característica de formação aligeirada apropriada pelos cursos de Pedagogia após a implementação das Diretrizes Curriculares Nacionais.

É a partir desta discussão que chegamos, assim, à temática central deste artigo, sendo ele uma defesa ao processo formativo de professoras como meio de construção de um sentido reflexivo ao "ser professor". Que possibilidades, assim, caminhariam na contramão de uma educação superior polivante e aligeirada?

Não encontramos uma única resposta a esta questão, mas sim uma interessante alternativa, já anunciada em momento anterior: a escrita como modo de pensar. É precisamente a este respeito que desenvolveremos nossas reflexões. 


\section{Escrever para pensar}

Quem de nós, professores e professores em formação, já se dedicou a, em algum momento a escrever diário? Cartas? Bilhetinhos? Enfim, uma pergunta que quer resposta afirmativa e o fato de não vermos o leitor nos ajuda a apenas inferir sobre um longo "eu já escrevi sim". Perguntamos para provocar a memória, já que escrever sempre foi prática exigida em nossa extensa vida escolar: escrever para contar sobre férias, para fazer uma composição ou até mesmo para "castigar" alguma ação entendida como negativa. E que triste pensar que escrever, em algum momento, pôde ser castigo!

Debater sobre a escrita na formação de professores é um movimento que nos exige pensar a relação que cada um tem com esta escrita. Isto porque não estamos nos referindo, aqui, a um ato de escrever que representa pura e simplesmente o deslizar de um lápis sob a folha de papel; ou a batida dos dedos no teclado do computador. Estamos, sim, expressando um ato que atrela a materialização do pensamento em palavras escritas à reflexão. Escrever e refletir! Mais que isso: escrever para refletir!

Escrever sobre a prática docente faz parte do cotidiano de alguns professores, seja de maneira individual ou coletiva, de forma assídua ou esporádica. É uma escrita que não possui forma única, mas carrega consigo algo de particularidade de cada um, de modo de pensar sobre o cotidiano escolar. A ideia sobre a escrita da prática - aqui entendida também como registro reflexivo - parte justamente do pressuposto de que tal escrita não tem forma única para ser elaborada, abrindo espaço para discutir e pensar sobre a descrição (sim, descrição!) e a reflexão do vivido quando na docência, temática central deste artigo.

As discussões sobre escrita reflexiva aqui apresentadas são derivadas de pesquisa de mestrado, buscando um olhar para as possíveis contribuições do registro escrito a professoras em formação. A partir de interlocuções teórico-práticas, buscamos avançar no debate sobre a escrita reflexiva, compreendendo suas possibilidades enquanto meio de oportunizar um revisitar da prática docente.

Buscamos, então, nas escritas de um grupo de seis estagiárias, sujeitos da pesquisa aqui discutida, a fonte dos materiais a serem analisados. Tais estagiárias foram solicitadas, por suas orientadoras de estágio, a registrar reflexivamente suas práticas docentes dentro do universo escolar quando na realização do estágio obrigatório, mais especificamente da disciplina de Estágio dos Anos Iniciais do Ensino Fundamental, lotada no oitavo semestre do curso de Pedagogia. Vale salientar que por ocasião da coleta dos dados empíricos, os sujeitos estavam organizados ou em duplas de estágio, alternativa possibilitada pela coordenação do curso diante do grande contingente de estagiárias, ou individualmente. No caso deste estudo, os sujeitos se organizaram em duas duplas e outras duas estagiárias de forma individual, compondo um total de quatro grupos de registros reflexivos. Tais registros foram elaborados a partir das escolhas feitas pelas estagiárias sobre o que e de que forma registrar, narrando sobre os desafios e as experiências dentro da escola no percurso do estágio obrigatório.

No contexto das discussões a que nos propomos, algumas perguntas são relevantes e orientam nosso pensar: o ato de apenas descrever as atividades realizadas em sala de aula com as crianças contribui para o processo de reflexão? Quais compreensões sobre o registro reflexivo são apresentadas nas escritas dos sujeitos da pesquisa? Que possíveis contribuições exerce a escrita reflexiva na constituição de professoras em formação? São apenas algumas perguntas impulsionam pensar possibilidades sobre a reflexão da prática por meio da escrita no curso de graduação e 
também ao longo da profissão docente. Rumemos, então, atrás de algumas (possíveis) respostas.

Importa esclarecer, aqui, que os sujeitos da pesquisa serão tratados pelos termos "estagiárias" e "professoras em formação", por compreendemos que essa era a função assumida por elas no momento da produção dos dados. No presente artigo foram analisadas as escritas construídas diariamente pelas estagiárias ao longo do processo de estágio, sendo um total de oitenta e seis produções que tiveram como foco o registro das vivências realizadas em sala de aula. São os chamados registros reflexivos, material construído com o objetivo de avaliar parcialmente a disciplina de Estágio dos Anos Iniciais do Ensino Fundamental, caracterizando-se enquanto corpus de análise.

As discussões que emergiram da análise dos dados e que são aqui problematizadas envolvem alguns saberes e fazeres das professoras em formação, bem como suas reflexões acerca das atividades realizadas junto à turma de estágio. Para aprofundar essas discussões, buscamos aliar as compreensões sobre escrita e registro de Marques (2011), Ostetto (2001) e Warschauer (1993/ 2001) às interlocuções com os dados empíricos, ou seja, os registros reflexivos.

A metodologia escolhida para respaldar a análise dos dados foi a chamada Análise Textual Discursiva - ATD, cunhada por Moraes e Galiazzi (2007). Esta metodologia está organizada em três procedimentos básicos: unitarização, categorização e construção de metatextos. Nas páginas seguintes trazemos os diálogos construídos a partir das reflexões dos sujeitos e das interações tecidas junto aos teóricos escolhidos para respaldar a pesquisa, tecendo, assim, as análises por nós construídas.

Cabe esclarecer que a aposta do presente artigo é de que o registro reflexivo contribui para o movimento de reflexão sobre a prática, possibilitando diferentes aprendizagens para as professoras em formação mesmo apresentando, na maioria das vezes, um caráter descritivo. Isto porque tal registro é diferente da escrita das situações cotidianas e do universo escolar, uma vez que escrever sobre atividades realizadas tem um tom mais descritivo, extenso, porém complementar às reflexões, pois traz os fatos de maneira detalhada possibilitando o repensar de ações no momento da prática de sala de aula.

Muitos são os fragmentos encontrados nos escritos das estagiárias que apresentam descrição das atividades, trazendo para a escrita elementos do cotidiano, permitindo que um dado acontecido seja registrado e relembrado e, desta forma, contribuindo para a reflexão. Segundo Cecília Warschauer (1993) as descrições caracterizam-se como alimento e embasamento para a reflexão, questões que contribuem com a escrita reflexiva enquanto instrumento que possibilita o planejamento e a avaliação.

O artigo está organizado em três momentos, sendo eles: (1) a descrição das atividades no registro reflexivo; (3) planejamento a partir do registro, elementos para a reflexão e para a ação; e por fim (4) considerações finais que expressam as possíveis contribuições e aprendizagens possibilitados pela discussão.

Já no outro momento, entregamos a poesia para os educandos e pedimos que lessem silenciosamente. Logo em seguida, questionamos sobre o que se tratava a poesia e fomos complementando, explicamos algumas frases da mesma (Marina e Ana).

O processo de idas e vindas na leitura dos registros reflexivos produzidos pelas professoras em formação possibilita compreender que, ao construí-los, utilizaram-se da descrição dos fatos, principalmente trazendo para a escrita diversos elementos de cada 
atividade realizada nas aulas, tal como pode ser observado no fragmento citado acima. Esta abordagem inicialmente nos parecia pouco intensa, pois acabávamos por entender, quando na análise dos dados, que fragmentos meramente descritivos pouco contribuíam para um ato reflexivo sobre a ação pedagógica. Ou seja, atribuíamos um juízo de valores à escrita das estagiárias.

Assim, reflexivo parecia-nos tudo o que estava para além da descrição, apontando modos de sentir e de pensar determinada vivência em sala de aula. Foi preciso, porém, olhar não para além da descrição, mas para além de nossos próprios entendimentos. Isso porque percurso da pesquisa possibilitou-nos compreender que o ato de escrever descrevendo poderia sim contribuir na elaboração registros reflexivos, já que, segundo Warshauer $(1993,2001)$ e Ostetto (2001), este é composto por aspectos analíticos e também descritivos.

Dessa forma, alargarmos nossa compreensão, tentando sermos sensíveis para entender o que as escritas das professoras em formação mostravam-nos. Percebemos assim, a recorrência de fragmentos compreendidos enquanto descritivos, artifício utilizado por todas as estagiárias ao escrever sobre a prática. São escritas em que a descrição das atividades aparece como comunicação do que é feito, registro do vivido, trazendo para o texto, detalhes das práticas. Ou seja, as professoras em formação registram, por exemplo, as perguntas feitas pelas crianças em determinada atividade e o desenvolvimento de dinâmicas e de propostas. Isso pode ser percebido nas palavras de Marcela:

A aula hoje iniciou com a trilha das operações, as crianças se dividiram nas suas equipes, para iniciar o jogo, a empolgação deu espaço ao silêncio e muitas contas, a ansiedade na hora da correção do cálculo me mostrava de alguma forma a maneira que estavam compenetrados no jogo, faziam e refaziam o cálculo várias vezes para ter certeza de que a resposta estava correta.

No fragmento acima, fica evidente a maneira descritiva escolhida por Marcela para contar sobre a aula. Ela expõe como ocorreu uma atividade proposta, contemplando a organização em grupos, a postura das crianças e ainda a percepção dela sobre a concentração da turma. Essa forma de escrita está relacionada às discussões tecidas por Warschauer (1993, p. 61) quando narra sua experiência ao produzir registros escritos, compreendendo a descrição enquanto aliada da reflexão:

Verifico que nos primeiros anos a maior preocupação era a de escrever fatos, atividades e comportamentos, meus e dos alunos. Posteriormente, passei a registrar mais os pensamentos sobre os fatos, sobre os sentimentos e sobre os próprios pensamentos, além das avaliações e planejamentos. Portanto, a reflexão sobre o vivido foi se aprofundando e, através dela, pude encontrar soluções criativas para os problemas que apareciam. As descrições continuavam ocorrendo, porém, serviam como embasamento e alimento para as reflexões.

A partir do dito pela autora, é possível perceber que a descrição tem espaço significativo dentro do registro, pois se caracteriza enquanto alimento para a reflexão. Registrar o desenvolvimento detalhado da atividade ilustra a aula desenvolvida, possibilitando um certo estranhamento do vivido e olhando para a experiência ida com um maior vagar. Isso porque escrever, em si, exige um tanto de desaceleração do tempo, 
escolha para dedicar-se à escrita e à rememoração do que ocorreu em sala de aula. Postura, esta, importante para a compreensão e para a reflexão.

Assim, é interessante ressaltar que a descrição é alimento para a reflexão, ilustrando vivências, narrando seus elementos. Eis, aqui, um importante elemento encontrado nos registros das professoras em formação: suas experiências eram constantemente ilustradas ao irem escrevendo minúcias do ocorrido em sala de aula, como que levando o leitor a pisar no espaço escolar junto com elas. Por meio do ato de rememorar as ações de sala de aula, contavam suas experiências e construíam elementos para sobre elas refletirem.

Construir o registro, assim, nas palavras de Ostetto (2001), não é apenas "contar o que aconteceu", mas buscar compreender e aprender com o vivido, afirmação que ganha relevância a partir do exposto por Marina e Ana, quando escrevem acerca de uma determinada atividade:

Iniciamos pedindo que cada um relatassem sobre o que acharam de mais significativos no filme e após fomos fazendo alguns questionamentos, como era a turma? Como estavam no final? O que houve para acontecer essa mudança? Como usavam os diários? E que diferentes culturas foi possível reconhecer no filme?

Por meio do registro das perguntas sobre o filme, as professoras em formação puderam, acreditamos, (re) pensar a ação pedagógica, questionando se as perguntas foram adequadas, se os objetivos foram alcançados e qual a sua repercussão no grupo de alunos. Como bem expressa Warschauer (1993, p.35), "[...] neste momento, o professor toma uma distância de seus atos e da realidade da sala de aula, de forma a distinguir-se do vivido para olhá-lo de uma forma particular". Sendo assim, o registro consiste em um (re) pensar sobre a ação pedagógica, apresentando um caráter avaliativo.

Ao construir o registro reflexivo, as professoras em formação também aproximam a orientadora do estágio da prática que realizam quando na ação docente junto às crianças, principalmente quando narram as atividades com detalhes, ilustrando a prática educativa e as posturas assumidas diante de cada situação. Na escrita de Amanda e Carla, a participação da orientadora é ainda mais efetiva, pois além da professora fazer a leitura do material escrito e, assim, conhecer um pouco mais do cotidiano em que as estagiárias estão inseridas, ela ainda estabelece um diálogo com as mesmas dentro do próprio texto, encaminhando algumas questões para a reflexão, tal como é evidenciado abaixo.

Outra atividade que teve destaque no dia de hoje foi à construção do texto Uma visita inesperada, através da visualização da imagem. Nessa, tivemos que selecionar algumas ideias para conseguirmos construir o texto com mais clareza e percebemos que o texto ficou bem desenvolvido. Esses momentos são importantes para o grupo perceber que precisamos fazer escolhas e respeitar as ideias dos demais colegas. Que bom que consideraram a atividade interessante. Apenas peço que pensem se a construção de histórias por meio de imagens não deixa a produção um tanto que limitada ${ }^{3}$.

O expresso acima contribui para pensarmos sobre a participação da professora orientadora a partir da escrita. Como é apresentado no fragmento acima, a orientadora lança uma reflexão que poderia ter sido "perdida" caso não fosse registrada, já que na 
multiplicidade de experiências vivenciadas no cotidiano, várias questões podem ser desprivilegiadas quando no diálogo oral durante os encontros de orientação, uma vez que são encontros breves, não ultrapassando 60 minutos, em sua maioria. Na escrita, a compreensão da orientadora é facilitada pela descrição das atividades, pois elas aparecem de forma detalhada, possibilitando que a professora tenha dimensão das vivências das professoras em formação quando em sala de aula e permitindo um "diálogo" sobre o que pode parecer simples acontecimentos.

Ao escreverem sobre suas posturas frente às atividades realizadas, as estagiárias, também aproximam-se do significado daquilo que fizeram, pensando sobre suas escolhas e trazendo à emergência a ilustração do vivido na sala de aula. Na escrita sobre a prática, ampliam a compreensão sobre suas ações, percebendo o movimento da sala de aula, da turma, refletindo sobre o que é preciso modificar e colocando em evidências aquilo que "deu certo" e que, portanto, merece lugar de destaque no registro.

No rastro do registro das ações que "deram certo", assim, as estagiárias pensam sobre a turma e sobre o planejamento de suas próximas aulas, pois além de avaliar o trabalho realizado podem também projetar as próximas ações. O registro das atividades de sucesso é recorrente nas escritas dos sujeitos da pesquisa, como é o caso citado por Maria:

Então que comecei a brincadeira dizendo: agora quero que 6 alunos venham aqui na frente. Mais do que prontamente haviam 8 alunos na frente, então os deixei lá. E comecei a falar se tenho 8 balões, ai peguei a minha lapiseira de ponta fina e tirar 3 balóes, furei os balões, foi um pulo só e muitos risos, com quantos balões eu fico. $\mathrm{E}$ todos me disseram: entre risos, fica com 5 balões, tia. Assim desenvolvi esta atividade, que me pareceu muito boa e até um aluno me disse: tia, depois desta aula de subtração, com os balões, não vou esquecer mais como se faz as contas.

Quando a estagiária descreve com detalhes uma atividade que teve repercussão positiva na turma, ela possibilita refletir sobre as características desta turma e, assim, entender que ações podem ser mantidas e que ações poderiam ser reconfiguradas. Além disso, traz à evidência modos de aprender de diferentes sujeitos ao eleger falas que materializam o pensamento de algumas crianças. Assim, compreendemos que o que levou a estagiária a caracterizar a atividade que propôs como "muito boa" foi justamente à expressão de uma das crianças de que a ludicidade com que ensinou subtração não a fará esquecer "como se faz as contas".

Entra em questão, aqui, não apenas a afirmação daquilo que "deu certo em sala de aula" mas, sobretudo, a ideia sobre ensinar e aprender que vai-se construindo no próprio movimento da docência, apontando para o que diz Warschauer (2001) ao expressar que através da escrita as estagiárias podem conhecer mais e elaborar com maior clareza suas concepções e compreensões sobre a docência.

As interlocuções, teórico-práticas tecidas até o momento permitiram encaminhar compreensões para pensar de que maneira a prática da escrita pode contribuir na formação inicial de professores. Destacou-se, assim, a escrita descritiva presente no registro das estagiárias como modo de contar sobre o ocorrido em sala de aula e avaliar as ações pensadas, possibilitando-se dar outras nuances a planejamentos futuros.

Além disso, há, nos registros, o caráter de uma certa permanência do tempo sendo que a escrita, conforme aponta Warschauer (2001, p. 188) "[...] diferentemente da vivência, não se esgota no momento de sua realização, mas é infinita." Escrever chama 
à memória, revisita o passado e possibilita sua resignificação uma vez que o tempo de escrever e de ler o escrito não mais coincide com o tempo do vivido.

O registo possibilita, assim, o revisitar das práticas pedagógicas sempre que necessário, para que possam ser reutilizadas e reelaboradas. Sendo assim, no subtítulo a seguir propomos discussões a respeito das contribuições da escrita reflexiva enquanto instrumento que possibilita o planejamento e a avaliação através da interlocução com fragmentos dos registros escritos pelos sujeitos de pesquisa.

\section{Planejamento a partir do registro, elementos para a reflexão e para a ação}

Nesta data a professora regente ficou responsável por aplicar o planejamento, mas como não consegui realizar todas as atividades previstas para o dia anterior sugeri que seguíssemos com as atividades. Propus esta saída com o intuito de não quebrar com o trabalho que tenho desenvolvido na turma, a professora aceitou e juntas aplicamos as atividades (Marcela).

O planejamento e a avaliação do fazer pedagógico são questões indispensáveis ao professor e que por sua vez necessitam de estudo. Acreditamos que escrever sobre a prática possibilita reflexões que envolvem o fazer docente, problematizadas, neste artigo, a partir de teorizações sobre o registro reflexivo e de seu caráter descritivo.

Entra em foco, neste momento da escrita, também a descrição como modo motivar a avaliação para, então, traçar-se planejamentos. Momentos, estes, não necessariamente ordenados, mas que podem mesclar-se no ato reflexivo exigido pela prática docente. É o que podemos observar no relato de Marcela, quando se utiliza de uma certa artimanha para burlar o planejamento da professora regente de sua turma de estágio por avaliar que a continuidade das atividades que estava trabalhando com a turma seriam mais interessantes para as crianças. O registro, assim, "como instrumento de trabalho, o registro vem associado ao planejamento e à avaliação" (OSTETO, 2001, p. 23).

O registro escrito ainda tem como característica a permanência ao longo do tempo, ou seja, ele pode se constituir em aprendizado acessível à memória. O que se escolheu contar está ali, registrado, passível de ser revisitado quando necessário ou, quando desejável. Esse caráter de durabilidade proporcionado pela escrita (MARQUES, 2011), contribui para uma repercussão em longo prazo das reflexões, indo ao encontro do proposto por Warschauer (1993, pp. 62-63):

Este "ter presente" o já acontecido é de especial importância na transformação do agir, pois oferece o conhecimento de situações arquivadas na memória, capacitando o sujeito a uma resposta mais profunda, mais integradora e mais amadurecida, porque menos ingênua e mais experiente, de quem já aprendeu com a experiência. Refletir sobre o passado (e sobre o presente) é avaliar as próprias ações, o que auxilia na construção do novo. E o novo é a indicação do futuro. É o planejamento.

A descrição traz consigo os detalhes do vivido, tal como foi expresso em momento anterior deste artigo, permitindo sua análise e compreensão. Pode constituirse como, neste sentido, a mola propulsora para planejamentos futuros uma vez que possibilita um reencontro com o passado, avaliando as ações propostas, conforme expressa Warschauer (ibidem). A autora inspira pensamos o registro como um 
indicativo para planejamentos futuros a partir de um misto entre passado, presente e futuro.

No registro a seguir é possível ver esse movimento de análise sobre o vivido, a partir de um simples registro que indica alteração no planejamento.

Como tivemos que adaptar o planejamento no momento do texto, algumas atividades não conseguimos concluir como o caça-palavras e o cartaz com os bairros da cidade. Essas atividades serão realizadas nos próximos planejamentos (Marina e Ana).

Ao escrever sobre a adaptação do planejamento, justificando a alteração nas atividades que agora ficarão para outro dia, as estagiárias tem elementos para refletir sobre a quantidade de atividades propostas à turma e o tempo que dedicam a cada atividade. $\mathrm{O}$ registro em sim, porém, não garante tal reflexão sendo necessário um olhar atento à escrita enquanto modo de aprender e, para além disso, de pensar.

A análise dos registros das professoras em formação foi-nos ensinando modos de utilização da escrita como forma de pensar a sala de aula e a prática docente. As escolhas do que registrar aproximam-se no momento em que se utilizam de uma estrutura muito similar, reservadas, por certo, as particularidades de cada modo de escrever, para contar sobre a prática docente. Assim, é constante depararmo-nos com escritos que indicam mudança de planejamento e que trazem à tona dinâmicas referentes ao contexto da escola. Este último aspecto pode ser observado no registro de Maria:

Bem como dito antes, não consegui mais dar o planejado para a aula deste dia, principalmente após a vinda do recreio, e fizemos alguns exercícios do livro de português e após isso entregamos as lembranças de Páscoa, eu a professora regente saímos com eles para a saída da escola, onde os pais os esperavam.

Refletindo sobre as atividades realizadas, as professoras em formação aprendem a conhecer mais a turma, seus interesses, limites e peculiaridades. Questões que, quando registradas, são posicionadas em um lugar de estranhamento e de reflexão (WARSCHAUER,1993), como é o caso do expresso por Maria. "Não conseguir dar o planejado", coloca-a de frente com o fato de que um planejamento necessita ser flexível, não indicando certezas quanto ao que será vivenciado com uma turma. Neste mesmo registro, Maria expõe seu entendimento sobre a aula, demonstrando maior tranquilidade com a alteração do planejamento:

Apesar de não conseguir desenvolver o meu planejamento neste dia, posso dizer que aprendi muito e conheci melhor alguns alunos, pois consegui conversar com eles sem ter que me preocupar em dar matéria, exercícios e fazer leituras, não que os meus planejamentos sejam só isso, mas foi um momento ímpar, muito diferente do que eu esperava, posso dizer que eu gostei muito.

Com o tempo e com a prática de escrita já incorporada em seu fazer, as estagiárias foram sentindo-se mais autorizadas a refletir, indo além da descrição dos fatos ocorridos, analisando-os e aprendendo com eles. Aprendizagens sobre o cotidiano, sobre os alunos, sobre ser professora e estar na escola, como expressa Maria em seu registro, que vai sendo qualificado e elaborado com maior clareza através da reflexão escrita (Warschauer, 2001). 
Esse movimento de qualificação e elaboração de compreensões sobre a docência proposto pela autora também é possível observar quando as estagiárias escrevem sobre as alterações feitas no planejamento, seja por necessidade de organização da escola, ou por uma percepção delas sobre a turma e a atividade escolhida. É o que podemos ver nas palavras de Marcela ao dizer: "já me sinto completamente segura ao planejar, consigo ter ideia das atividades que serão bem aceitas e aquelas que não chamam muita atenção do grupo".

Assim, o planejamento pode ser entendido como processo, construído a partir de intencionalidades e percepções sobre o próprio trabalho, sobre a escola e principalmente em consonância com a turma. Neste sentido, tornamos a afirmar que o registro escrito contribui para o planejamento, pois quando dedicamos um tempo a pensar sobre a prática realizada, estamos também refletindo e fazendo uma espécie de balanço das atividades, das propostas e das posturas junto às crianças. Questões como estas contribuem para o planejar e o (re)planejar, a partir dos conhecimentos e experiências que vamos agregando ao repertório de vivências, qualificando cada vez mais o fazer docente.

A partir da interação com os escritos dos sujeitos da pesquisa, torna-se evidente a contribuição que a escrita reflexiva para a formação de professores, aqui discutida por meio da avaliação e do planejamento. Reiteramos, assim, o argumento que construímos no rastro de Warschauer $(1993,2001)$ e Ostetto (2001), ou seja, a descrição traz para a escrita elementos sobre cada uma das atividades realizadas quando em sala de aula, possibilitando que as estagiárias pensem sobre elas a partir da escrita de detalhes encaminhadores de reflexões. A descrição constitui-se, assim, em alimento para o registro reflexivo, oferecendo subsídios para pensar sobre a própria prática, avaliando o trabalho e projetando os próximos passos a serem planejados.

\section{Considerações finais}

Ao final desta escrita, algumas reflexões ainda são necessárias, pensamentos sobre as construções feitas ao longo do artigo e em que ele contribui para pensar sobre a escrita reflexiva na formação de professores. Questões que foram sendo debatidas e entrelaçadas às escritas dos sujeitos da pesquisa e aos interlocutores teóricos "chamados" para participar deste artigo. Assim, voltamos aos questionamentos iniciais, pois foram eles que orientaram as discussões feitas até aqui: quais compreensões sobre o registro reflexivo são apresentadas nas escritas dos sujeitos da pesquisa? Que possíveis contribuições exerce a escrita reflexiva na constituição de professoras em formação?

Ao construir os registros, as professoras em formação não utilizam um único formato, encontrando uma forma peculiar para fazê-lo, de acordo com suas compreensões. Contudo, algumas questões comuns são observáveis, como é o caso do artifício da descrição dos fatos, o qual traz para a escrita diversos elementos de cada atividade realizada nas aulas, ato que vem a ser motivador da reflexão, já que, segundo as teorizações feitas, o registro reflexivo é composto por aspectos descritivos e analíticos.

A escrita sobre a prática docente de modo descritivo contribui também para o planejamento e a avaliação processual do trabalho docente, como vimos no segundo subtítulo deste artigo. Destacamos ainda, o caráter de permanência da escrita, o qual possibilita o (re) pensar da docência, já que é possível revisitá-la sempre que necessário ou desejável indo além do tempo presente. 
As interlocuções teóricas construídas neste artigo permitem compreender de que maneira a prática da escrita pode contribuir com a formação docente, especialmente no que diz respeito à qualificação contínua da prática docente. Contudo, entendemos que ainda se façam necessários alguns avanços para que a escrita reflexiva se torne cada vez mais presente no cotidiano dos professores, já que esta se caracteriza enquanto temática importante para a formação docente.

Sobre os avanços que ainda podem ser feitos, pensamos que é relevante construir maior clareza e aprofundamento sobre a prática docente e a possibilidade de aliá-la à produção escrita como ferramenta para pensá-la dentro dos espaços de formação docente, para que essa prática seja difundida por tais espaços, possibilitando que as professoras em formação aprendam sobre a escrita reflexiva e suas contribuições, podendo assim incorporá-las em seu fazer.

Os debates promovidos neste artigo, acreditamos, podem contribuir para pensarmos sobre as potencialidades do ato de escrever a respeito da prática docente, $o$ que possibilita as professoras em formação a reflexão e a qualificação de seu trabalho.

\section{Referências}

MARQUES, Mario Osorio; Escrever é preciso: o princípio da pesquisa / Mario Osorio Marques. - 2.ed. - Petrópolis, RJ: Vozes, 2011. - 157p.

MORAES, Roque; GALIAZZI, Maria do Carmo. Análise textual discursiva. Ijuí: Ed. Unijuí, 2007.

OSTETTO, Luciana E. Deixando marcas - a prática do registro do cotidiano da educação infantil / Luciana Esmeralda Ostetto, Eloisa Raquel de Oliveira, Virginia da silva Messina. - Florianópolis: Cidade Futura, 2001.

SAVIANI, Dermeval. Escola e Democracia. 38. ed. Campinas, SP: Autores Associados, 2006.

SCHEIBE, L. Diretrizes curriculares para o curso de pedagogia: trajetória longa e inconclusa. Cadernos de Pesquisa, v. 37, n.130, p. 43-62, jan. 2007

VIEIRA, Suzane. Diretrizes curriculares para o curso de pedagogia: pedagogo, docente ou professor? Dissertação de Mestrado. Universidade Federal de Santa Catarina. Programa de Pós-Graduação em Educação, 2007.

WARSCHAUER, Cecília. A roda e o registro: uma parceria entre professor, alunos e conhecimento / Cecília Warschauer. - Rio de Janeiro: Paz e Terra, 1993.

WARSCHAUER, Cecília. Rodas em rede: oportunidades formativas na escola e fora dela. Rio de Janeiro: Paz e Terra, 2001. 
Notas

${ }^{1}$ Universidade Federal do Rio Grande-FURG.

${ }^{2}$ Docente da Universidade Federal do Rio Grande-FURG.

${ }^{3}$ Em negrito estão as palavras da orientadora de estágio. Característica apresentada por apenas uma dupla de estagiárias, porém bastante significativa por representar a participação da professora de maneira efetiva através do diálogo no material.

Recebido: Março/2016.

Aprovado: Junho/2017. 